\title{
Lethality-Associated Factors in Deliberate Self-Poisoning
}

\author{
In Young Choi', Sun-Young Kim², Jhin Goo Chang', Hoo Rim Song', \\ Woo Jung Kim ${ }^{3}$, Su Young Lee ${ }^{1}$, Hyun-Soo Kim', and Minha Hong ${ }^{1}$ \\ ${ }^{1}$ Department of Psychiatry, Myongji Hospital, Hanyang University College of Medicine, Goyang, Korea \\ ${ }^{2}$ Department of Cancer Control and Population Health, Graduate School of Cancer Science and Policy, National Cancer Center, \\ Goyang, Korea \\ ${ }^{3}$ Department of Psychiatry, Yongin Severance Hospital, Yonsei University College of Medicine, Youngin, Korea
}

\begin{abstract}
Objectives: Deliberate self-poisoning (DSP) is the most common suicide method and can be life-threatening. The purpose of this study was to investigate the factors related to the lethality of DSP and the characteristics of the adolescent group.

Methods: A retrospective study was conducted on patients who had visited an academic hospital's regional emergency medical center between 2015 and 2018. The data reviewed through their medical records included sociodemographic factors, clinical variables, and psychiatric treatment. Four groups (Q1-Q4) were categorized by descriptive analysis using the risk-rescue rating scale.

Results: A total of 491 patients were enrolled in this study. This study showed that high lethality had statistically significant associations with male sex, older age, admitting suicidal intentions, and the use of herbicides for suicide. Logistic regression analyses showed a significant association between high-lethality and female [odds ratio $(\mathrm{OR})=0.50,95 \%$ confidence interval $(\mathrm{CI})=0.30-0.81, \mathrm{p}=0.01$ ], non-psychiatric drugs (over-the-counter drug: $\mathrm{OR}=2.49,95 \% \mathrm{CI}=1.08-5.74, \mathrm{p}=0.03$; herbicide: $\mathrm{OR}=8.65,95 \% \mathrm{CI}=3.91-19.13, \mathrm{p}<0.01$ ), and denial of suicide intent $(\mathrm{OR}=0.28,95 \% \mathrm{CI}=0.15-0.55, \mathrm{p}<0.01)$.

Conclusion: This study showed the clinical factors associated with the high lethality of DSP and suggested that efforts were needed to care for and thoroughly examine patients with DSP.
\end{abstract}

Key Words: Drug intoxication; Deliberate self-poisoning; Lethality; Risk-rescue rating scale.

Received: August 19, 2020 / Revision: September 8, 2020 / Accepted: October 8, 2020

Address for correspondence: Minha Hong, Department of Psychiatry, Myongji Hospital, Hanyang University of College of Medicine, 55 Hwasu-ro 14beon-gil, Deokyang-gu, Goyang 10475, Korea

Tel: +82-31-810-6230, Fax: +82-31-969-0500, E-mail: npmhhong@gmail.com

\section{INTRODUCTION}

Suicide in Korea has been widely recognized as a serious social issue. The suicide rate of 23 per 100000 people in Korea is more than double the average of the Organisation for Economic Cooperation and Development (OECD) countries, which is 11.9 per 100000 . Although it has been decreasing since 2011, Korea retains the second-highest suicide rate among OECD countries [1]. Studies on suicide have primarily focused on the issues of social losses, methods, and gender differences [2]. Suicides by self-poisoning account for $30 \%$ of deaths worldwide [3], with poisonous drugs, mainly pesticides being the most common suicide methods in Asia, including Korea. However, there is still a lack of research focused on self-poisoning itself. Deliberate self-poisoning (DSP) is associated with an increased risk of further suicidal behavior [4] and premature death [5].

This is an Open Access article distributed under the terms of the Creative Commons Attribution Non-Commercial License (https://creativecommons.org/licenses/by-nc/4.0) which permits unrestricted non-commercial use, distribution, and reproduction in any medium, provided the original work is properly cited.
Non-suicidal self-injury (NSSI) is most commonly defined as the deliberate destruction of one's body without suicidal intent [6]. NSSI is common, with a lifetime prevalence of $17.2 \%$ among adolescents and $13.4 \%$ among young adults [7]. The incidence and rate of suicide attempts and NSSI using selfpoisoning in children less than 19 years old increased significantly after 2011. There has been an increase in the severity of outcomes independent of age or sex [8]. The leading cause of death in Korean adolescents has been suicide for 10 years [1]. The adolescent suicide rate increased on an average by about $5.2 \%$ per year for five years [9]. Juvenile suicide appears to be more serious in that the increasing trend is higher than that of other ages.

As a means of self-harm and suicide attempts in 2018, the rate of DSP was the highest among all age groups over 10 years of age (for those under nine years old, bumps were the highest) [9].

Self-poisoning in adolescence is a strong predictor of suicide and premature death in the ensuing decade and identifies a high-risk group for targeted secondary prevention. Sui- 
cide risk has increased for many years after the index hospital admission, emphasizing the importance of sustained prevention efforts [10]. However, there is a dearth of research that has investigated the factors related to the lethality of DSP, especially in adolescents in Korea.

The purpose of this study was to investigate the factors related to the lethality of DSP in those adolescents who visited the emergency department (ED) because of self-poisoning and analyze the characteristics of the adolescent group.

\section{METHODS}

\section{Study design and procedure}

The study was conducted in an urban academic hospital's emergency medical center (one of Korea's 36 regional emergency medical centers) that provides training to residents and board-certified faculties of various departments. The study was conducted by retrospectively reviewing medical records and was approved by the Institutional Review Board of Myong Ji Hospital (IRB No. 2019-10-013-003).

The management of patients with DSP involves two main processes: assessment of the patient's medical condition and evaluation of their psychiatric condition. First, all patients with DSP are initially assessed by an ED resident, who checks their mental status and vital signs as well as routine laboratory test reports, including blood ethanol levels, chest X-ray, electrocardiogram, and arterial blood gas analysis. In addition, information was collected from the patients' caregivers to assess the medical necessity for inpatient treatment in ED and other departments through toxicological evaluations such as the half-life of the poisonous drugs. Depending on the time of ingestion and the quantity and type of poisonous drugs, antidote administrations and treatment such as L-tube irrigation and hydration were performed.

The psychiatrist on duty assesses the risk of self-harm and suicide by interviewing the patient and the accompanying family members and decides on whether to recommend inpatient or outpatient psychiatric treatment.

In an ED setting, to determine whether patients with DSP need medical attention or psychiatric assessment and treatment, they should be assessed by collecting basic information on their premorbid personality, psychiatric history, past or recent suicide attempts, expressed suicidal intent, stressful events that can trigger a suicidal crisis, and warning signs of suicide.

\section{Study population}

We retrospectively reviewed the medical records of patients who had visited the ED because of DSP and had undergone psychiatric interviewing between January 1, 2015, and December 31, 2018. Self-poisoning is defined as the deliberate ingestion of more than the prescribed amount of a medical substance or a substance not meant for human consumption, irrespective of the motive for the episode [11]. We extracted medical records using the International Classification of Diseases-Tenth Revision (ICD-10) diagnostic code, viz. X60-69 (intentional self-harm by hanging, strangulation, and suffocation).

\section{Measurements}

Mortality was assessed using the risk-rescue rating scale (RRRS) [12], whose psychometric properties had been previously validated [13]. The RRRS comprises two subscales: 1) "risk factors" which include the method used, impairment of consciousness, toxicity, reversibility, and treatment required; 2) "rescue factors" that include the location, person initiating the rescue, probability of discovery, accessibility of rescue, and delay until discovery. Each of the ten items was scored as 1,2, or 3. The total risk (or rescue) points were calculated by summing the score of each item to achieve a total score of 5-15 points. The total risk (or rescue) points were then converted to an overall risk (or rescue) score ranging from 1 to 5 . Higher risk scores indicated more lethal suicide attempts, whereas higher rescue scores meant less serious and more easily rescued suicide attempts. The final RRRS score is expressed as the ratio of the risk score to the total risk and rescue score [13].

RRRS was categorized into quartiles (Q1-Q4) based on the distribution. The first quartile group Q1 was defined as less than or equal to, 40 , the value of the bottom $25 \%$. Q2, Q3, and Q4 were defined as greater than 40,50 , and 57 , respectively, which correspond to $25 \%, 50 \%$, and $75 \%$, respectively. We created a binary variable using a 50\% cutoff for the logistic regression analysis to assess the association with different individual variables.

\section{Socio-demographic and clinical characteristics}

Sex and age were examined to determine the sociodemographic variables associated with lethality. The ages were grouped by 10 -year intervals. The patients' arrival time at the ED was divided into six-hour intervals such as $0-6,6-12$, $12-18$, and $18-24$. We measured the patient's condition on arrival, such as the association of co-ingested alcohol with DSP and blood ethanol levels. The blood alcohol concentrations were divided into 3 groups: none, below $150 \mathrm{mg} / \mathrm{dL}$, and above $150 \mathrm{mg} / \mathrm{dL}$ [14]. The precipitating factors that can trigger a DSP were categorized into 1) couple relationship problems; 2) stress from job or school; 3) family relationship problems; 4) unemployment or economic problems; 5) chronic physical illness; 6) psychiatric symptoms; 7) others-sexual trauma, vic- 
IY Choi, et al.

Table 1. Characteristics of patients with deliberate self-poisoning $(n=491)$

\begin{tabular}{|c|c|c|c|c|}
\hline Characteristics & Adolescents $(n=76)$ & Adults $(n=340)$ & Elderly $(n=75)$ & Total $(n=491)$ \\
\hline Age $(y r$, mean $\pm S D)$ & $20.03 \pm 2.96$ & $45.89 \pm 10.55$ & $75.35 \pm 10.71$ & $46.50 \pm 18.24$ \\
\hline \multicolumn{5}{|l|}{ Sex } \\
\hline Male & $24(31.6)$ & $100(29.4)$ & $45(60.0)$ & $169(34.4)$ \\
\hline Female & $52(68.4)$ & $240(70.6)$ & $30(40.0)$ & $322(65.6)$ \\
\hline \multicolumn{5}{|l|}{ Visit time (hour) } \\
\hline $0-6$ & $22(28.9)$ & $81(23.8)$ & $8(10.7)$ & $111(22.6)$ \\
\hline $6-12$ & $14(18.4)$ & $44(12.9)$ & $17(22.7)$ & $75(15.3)$ \\
\hline $12-18$ & $21(27.6)$ & $93(27.4)$ & $28(37.3)$ & $142(28.9)$ \\
\hline $18-24$ & $19(25)$ & $122(35.9)$ & $22(29.3)$ & $163(33.2)$ \\
\hline \multicolumn{5}{|l|}{ Emergency room discharge results } \\
\hline Discharge against medical advice & $24(31.6)$ & $135(39.7)$ & $9(12)$ & $168(34.2)$ \\
\hline Symptom improvement & $14(18.4)$ & $29(8.5)$ & $7(9.3)$ & $50(10.2)$ \\
\hline Psychiatric admission & $5(6.6)$ & $24(7.1)$ & $4(5.3)$ & $33(6.7)$ \\
\hline Medical department admission & $33(43.4)$ & $152(44.7)$ & $55(73.3)$ & $240(48.9)$ \\
\hline \multicolumn{5}{|l|}{ Trigger events } \\
\hline Couple relationship problems & $15(19.7)$ & $34(10)$ & $0(0)$ & $49(10.0)$ \\
\hline Stress from job or school & $12(15.8)$ & $17(5)$ & $0(0)$ & $29(5.9)$ \\
\hline Family relationship problems & $20(26.3)$ & $133(39.1)$ & $33(44)$ & $186(37.9)$ \\
\hline Unemployment or economic problems & $4(5.3)$ & $45(13.2)$ & $8(10.7)$ & $57(11.6)$ \\
\hline Chronic physical illness & $0(0)$ & $7(2.1)$ & $17(22.7)$ & $24(4.9)$ \\
\hline Psychiatric symptoms & $9(11.8)$ & $36(10.6)$ & $7(9.3)$ & $52(10.6)$ \\
\hline Others & $3(3.9)$ & $4(1.2)$ & $1(1.3)$ & $8(1.6)$ \\
\hline Unknown & $13(17.1)$ & $64(18.8)$ & $9(12)$ & $86(17.5)$ \\
\hline \multicolumn{5}{|l|}{ Type of poisoning drugs } \\
\hline Psychiatric drugs & $40(52.6)$ & $160(47.1)$ & $18(24)$ & $218(44.4)$ \\
\hline Other prescribed drugs & $2(2.6)$ & $83(24.4)$ & $19(25.3)$ & $104(21.2)$ \\
\hline OTC drugs & $30(39.5)$ & $59(17.4)$ & $0(0)$ & $89(18.1)$ \\
\hline Herbicides & $4(5.3)$ & $38(11.2)$ & $38(50.7)$ & $80(16.3)$ \\
\hline \multicolumn{5}{|l|}{ Blood alcohol levels (mg/dL) } \\
\hline 0 & $62(81.6)$ & $189(55.6)$ & $57(76)$ & $308(62.7)$ \\
\hline-150 & $12(15.8)$ & $76(22.4)$ & $11(14.7)$ & $99(20.2)$ \\
\hline$>150$ & $2(2.6)$ & $75(22.1)$ & $7(9.3)$ & $84(17.1)$ \\
\hline \multicolumn{5}{|l|}{ Suicide attempt intent } \\
\hline Yes & $39(51.3)$ & $137(40.3)$ & $48(64)$ & $224(45.6)$ \\
\hline No & $20(26.3)$ & $111(32.6)$ & $13(17.3)$ & $144(29.3)$ \\
\hline Unchecked & $17(22.4)$ & $92(27.1)$ & $14(18.7)$ & $123(25.1)$ \\
\hline \multicolumn{5}{|l|}{ Previous psychiatric treatment history } \\
\hline None & $24(31.6)$ & $140(41.2)$ & $39(52)$ & $203(41.3)$ \\
\hline In treatment & $40(52.6)$ & $149(43.8)$ & $27(36)$ & $216(44)$ \\
\hline Previous history & $12(15.8)$ & $51(15)$ & $9(12)$ & $72(14.7)$ \\
\hline \multicolumn{5}{|l|}{ Previous psychiatric admission } \\
\hline None & $65(85.5)$ & $267(78.5)$ & $63(84)$ & $395(80.4)$ \\
\hline Once & $8(10.5)$ & $34(10)$ & $6(8)$ & $48(9.8)$ \\
\hline Multiple & $3(3.9)$ & $39(11.5)$ & $6(8)$ & $48(9.8)$ \\
\hline \multicolumn{5}{|l|}{ Last psychiatric outpatient visit } \\
\hline None & $24(31.6)$ & $140(41.2)$ & $39(52)$ & $203(41.3)$ \\
\hline Within one week & $13(17.1)$ & $49(14.4)$ & $6(8)$ & $68(13.8)$ \\
\hline Within one month & $27(35.5)$ & $100(29.4)$ & $21(28)$ & $148(30.1)$ \\
\hline More than one month & $12(15.8)$ & $51(15)$ & $9(12)$ & $72(14.7)$ \\
\hline
\end{tabular}


Table 1. Characteristics of patients with deliberate self-poisoning $(n=491)$ (continued)

\begin{tabular}{lcccc}
\hline \multicolumn{1}{c}{ Characteristics } & Adolescents $(\mathrm{n}=76)$ & Adults $(\mathrm{n}=340)$ & Elderly $(\mathrm{n}=75)$ & Total $(\mathrm{n}=491)$ \\
\hline $\begin{array}{l}\text { Previous suicide attempts } \\
\text { No }\end{array}$ & $56(73.7)$ & $250(73.5)$ & $61(81.3)$ & $367(74.7)$ \\
Yes & $20(26.3)$ & $90(26.5)$ & $14(18.7)$ & $124(25.3)$ \\
Number of outpatient visits after discharge & & & & \\
0 & $39(51.3)$ & $222(65.3)$ & $42(56)$ & $303(61.7)$ \\
$1-9$ & $27(35.5)$ & $92(27.1)$ & $25(33.3)$ & $144(29.3)$ \\
$10-$ & $10(13.2)$ & $26(7.6)$ & $8(10.7)$ & $44(9.0)$ \\
\hline
\end{tabular}

Data are presented as $n$ (\%). OTC drug: over-the-counter drugs (medicines sold directly to a consumer without a requirement for a prescription from a healthcare professional)

tims of crime; and 8) unknown. The presence of previous attempts was assessed dichotomously, and the number of previous suicide attempts was categorized into none, 1-9, and 10 or more.

The final exit from the emergency room of patients with DSP was classified into four categories: 1) Discharge Against Medical Advice (DAMA), in which, although the necessity for psychiatric inpatient treatment and outpatient hospital treatment for follow-up were explicitly explained, the patient refused treatment and completed the discharge pledge against medical advice; 2) symptom relief; 3) psychiatric inpatient treatment; and 4) admission to ED.

The psychiatric treatment history was assessed and grouped into three groups: 1) none; 2) in-treatment if the patient visited the psychiatric clinic; and 3) previous history if the patient had visited the psychiatric clinic, and/or dropped off. The previous psychiatric admission was also assessed and grouped as none, once, or multiple. The time since the last psychiatric outpatient visit was categorized into none, within a week, within a month, and more than one month. The adolescent (under 24 years) group was also analyzed separately.

\section{Treatment engagement and compliance}

No universal definition of treatment engagement has been used consistently across studies. However, we propose that the term refers to being committed to the therapeutic process and being an active participant in a collaborative relationship with a therapist to work to improve one's condition. Studies examining engagement in psychiatric treatment typically operationalize engagement in two ways: 1) whether or not the patient attended his or her first scheduled outpatient appointment or 2) the total number of sessions attended by the patient [15].

\section{Statistical analysis}

The summary statistics of the patients' baseline characteristics across the four groups of RRRS are presented as frequencies and percentages, along with chi-square tests and Fisher's exact tests when the sample size was small. To assess the relationship between individual characteristics and binary RRRS, we used a multivariable logistic regression model and estimated the odds ratios (OR) and 95\% confidence intervals (CIs). Logistic regression analysis was performed according to adolescent age. As the group of adolescents included a limited number of people, we included a limited set of variables compared to those for all age groups. All statistical analyses were performed using R v.3.6.2 (R Foundation for Statistical Computing, Vienna, Austria; https://www.Rproject.org/), and p-values less than 0.05 were considered significant.

\section{RESULTS}

\section{Characteristics of participants}

Of the 503 patients screened for DSP, 12 were excluded from the study due to incomplete medical records. In total, 491 patients were enrolled, comprising 169 (34.4\%) male and 322 (65.6\%) female, aged between 11-98 years old.

Table 1 presents their socio-demographic, clinical, and treatment characteristics. Psychiatric drugs were used most commonly ( $\mathrm{n}=218,44.4 \%)$ used in DSP, followed by drugs prescribed by other departments $(n=104,21.2 \%)$, over-thecounter (OTC) drugs $(n=89,18.1 \%)$, and herbicides $(n=80$, 16.3\%). According to the blood alcohol level routine work-up conducted in the ED, 308 (62.7\%) patients were not drunk, whereas $84(17.1 \%)$ patients had blood alcohol levels of 150 $\mathrm{mg} / \mathrm{dL}$ or higher. The number of patients who admitted and denied suicidal intent was 224 (45.6\%) and 144 (29.3\%), respectively. After discharge from the ED, 240 (48.9\%) were hospitalized in emergency medicine. Although the necessity for psychiatric treatment has been sufficiently explained, 168 (34.2\%) patients still opted for DAMA. According to past records of psychiatric outpatient visits, 148 (30.1\%) had visited a month ago, and 68 (13.8\%) had visited within a week (Table 1). 
IY Choi, et al.

Table 2. Comparison of sociodemographic and clinical characteristics of patients with deliberate self-poisoning by quartiles of RRRS $(n=491)$

\begin{tabular}{|c|c|c|c|c|c|c|}
\hline Variable & Q1 $(n=127)$ & Q2 $(n=235)$ & Q3 $(n=63)$ & Q4 $(n=66)$ & $\chi^{2}$ & $p$ \\
\hline Sex & & & & & 34.036 & $<0.001^{\ddagger}$ \\
\hline Male & $30(24)$ & $70(30)$ & $28(44)$ & $41(62)$ & & \\
\hline Female & $97(76)$ & $165(70)$ & $35(56)$ & $25(38)$ & & \\
\hline Age (yr) & & & & & 36.472 & $<0.01^{\dagger}$ \\
\hline-29 & $33(26)$ & $52(22)$ & $13(21)$ & $11(17)$ & & \\
\hline $30-39$ & $20(16)$ & $35(15)$ & $3(5)$ & $8(12)$ & & \\
\hline $40-49$ & $25(20)$ & $51(22)$ & $12(19)$ & $7(11)$ & & \\
\hline $50-59$ & $34(27)$ & $52(22)$ & $15(24)$ & $15(23)$ & & \\
\hline $60-69$ & $9(7)$ & $25(22)$ & $6(10)$ & $8(12)$ & & \\
\hline $70-$ & $6(5)$ & $20(9)$ & $14(22)$ & $17(26)$ & & \\
\hline Visit time (hour) & & & & & 7.230 & 0.613 \\
\hline $0-6$ & $34(27)$ & $49(21)$ & $12(19)$ & $16(24)$ & & \\
\hline $6-12$ & $21(17)$ & $32(14)$ & $13(21)$ & $9(14)$ & & \\
\hline $12-18$ & $29(23)$ & $78(33)$ & $18(29)$ & $17(26)$ & & \\
\hline $18-24$ & $43(34)$ & $76(32)$ & $20(32)$ & $24(36)$ & & \\
\hline Trigger event & & & & & 7.124 & 0.624 \\
\hline Interpersonal problems & $67(53)$ & $114(49)$ & $28(44)$ & $26(39)$ & & \\
\hline Economic and social problems & $15(12)$ & $44(19)$ & $14(22)$ & $13(20)$ & & \\
\hline Others & $21(17)$ & $37(16)$ & $12(19)$ & $14(21)$ & & \\
\hline Unknown & $24(19)$ & $40(17)$ & $9(14)$ & $13(20)$ & & \\
\hline Suicide intent expression & & & & & 40.270 & $<0.001^{\ddagger}$ \\
\hline Admit & $39(31)$ & $105(45)$ & $34(54)$ & $46(70)$ & & \\
\hline Denial & $58(46)$ & $69(29)$ & $11(17)$ & $6(9)$ & & \\
\hline Unmeasured & $30(24)$ & $61(26)$ & $18(29)$ & $14(21)$ & & \\
\hline Type of poisoning drug & & & & & 75.652 & $<0.001^{\ddagger}$ \\
\hline Psychiatric drugs & $69(54)$ & $117(50)$ & $15(24)$ & $17(26)$ & & \\
\hline Other prescribed drugs & $27(21)$ & $53(23)$ & $9(14)$ & $15(23)$ & & \\
\hline OTC drugs & $25(20)$ & $41(17)$ & $11(17)$ & $12(18)$ & & \\
\hline Herbicides & $6(5)$ & $24(10)$ & $28(44)$ & $22(33)$ & & \\
\hline Blood alcohol levels (mg/dL) & & & & & 3.069 & 0.800 \\
\hline 0 & $82(65)$ & $151(64)$ & $35(56)$ & $40(61)$ & & \\
\hline-150 & $22(17)$ & $48(20)$ & $14(22)$ & $15(23)$ & & \\
\hline$>150$ & $23(18)$ & $36(15)$ & $14(22)$ & $11(17)$ & & \\
\hline Psychiatric treatment history & & & & & 6.124 & 0.409 \\
\hline None & $56(44)$ & $97(41)$ & $34(54)$ & $35(53)$ & & \\
\hline In treatment & $57(45)$ & $112(48)$ & $21(33)$ & $25(38)$ & & \\
\hline Previous history & $14(11)$ & $26(11)$ & $8(13)$ & $6(9)$ & & \\
\hline Previous suicide attempt & & & & & 7.263 & 0.064 \\
\hline No & $103(81)$ & $163(69)$ & $50(79)$ & $51(77)$ & & \\
\hline Yes & $24(19)$ & $72(31)$ & $13(21)$ & $15(23)$ & & \\
\hline Previous psychiatric admission & & & & & 3.983 & 0.679 \\
\hline None & $103(81)$ & 185 (79) & $54(86)$ & $53(43)$ & & \\
\hline Once & $9(7)$ & $28(12)$ & $4(6)$ & $7(6)$ & & \\
\hline Multiple & $15(12)$ & $22(9)$ & $5(8)$ & $63(51)$ & & \\
\hline Last psychiatric outpatient visit & & & & & 9.053 & 0.432 \\
\hline None & $49(39)$ & $89(38)$ & $31(49)$ & $34(52)$ & & \\
\hline Within one week & $17(13)$ & $38(16)$ & $7(11)$ & $6(9)$ & & \\
\hline Within one month & $44(35)$ & $73(31)$ & $14(22)$ & $17(26)$ & & \\
\hline More than one month & $17(13)$ & $35(15)$ & $11(17)$ & $9(14)$ & & \\
\hline
\end{tabular}


Table 2. Comparison of sociodemographic and clinical characteristics of patients with deliberate self-poisoning by quartiles of RRRS $(n=491)$ (continued)

\begin{tabular}{|c|c|c|c|c|c|c|}
\hline Variable & Q1 $(n=127)$ & Q2 $(n=235)$ & Q3 $(n=63)$ & Q4 $(n=66)$ & $\chi^{2}$ & $p$ \\
\hline Psychiatric Treatment consent & & & & & 1.956 & 0.581 \\
\hline Refusal & $84(66)$ & $142(60)$ & $40(63)$ & $45(18)$ & & \\
\hline Consent & $43(34)$ & $93(40)$ & $23(37)$ & $210(82)$ & & \\
\hline Number of outpatient visits after discharge & & & & & 6.662 & 0.353 \\
\hline 0 & $75(59)$ & $143(61)$ & $38(60)$ & $47(71)$ & & \\
\hline $1-9$ & $43(34)$ & $65(28)$ & $20(32)$ & $16(24)$ & & \\
\hline $10-$ & $9(7)$ & $27(11)$ & $5(8)$ & $3(5)$ & & \\
\hline
\end{tabular}

\section{Relationship between individual characteristics and lethality}

Sex, age, type of poisonous drugs, and expression of suicidal intent were significantly related to the quartiles of RRRS $(\mathrm{p}<0.001, \mathrm{p}=0.001, \mathrm{p}<0.001$, and $\mathrm{p}<0.001$, respectively) (Table 2). The proportion of male participants was highest in Q4. Seventy percent of patients $(n=49)$ admitted that they had attempted suicide in Q4 compared to 31\% ( $n=39)$ in Q1. More than half of the patients $(\mathrm{n}=69,54 \%)$ had used psychiatric drug poisoning in Q1. In Q4, one-third of patients $(n=22$, $33 \%$ ) poisoned themselves with herbicides, as opposed to $5 \%$ $(\mathrm{n}=6)$ in Q1 (Table 2).

Logistic regression analyses revealed a negative association between binary RRRS and lethality in females compared to males ( $\mathrm{OR}=0.50,95 \% \mathrm{CI}=0.30-0.81, \mathrm{p}<0.01)$ and with denial of suicidal intent compared to admit $(\mathrm{OR}=0.28,95 \% \mathrm{CI}=$ $0.15-0.55, \mathrm{p}<0.01)$. High lethality was associated with the type of poisoning drugs: herbicides $(\mathrm{OR}=8.65,95 \% \mathrm{CI}=3.91-19.13$, $\mathrm{p}<0.01)$ and $\mathrm{OTC}$ drugs $(\mathrm{OR}=2.49,95 \% \mathrm{CI}=1.08-5.74, \mathrm{p}=0.03)$ compared to psychiatric drugs (Table 3 ).

In 75 patients in the adolescence and young adulthood groups (age $<24$ years), the mean age of the adolescent patients was $20.03 \pm 2.96$ years, with the youngest participant being 11 years. There were statistically significant relationships between sex and drinking status and the lethality of DSP measured by RRRS ( $\mathrm{p}=0.009$ and $\mathrm{p}=0.049$, respectively) (Table 4).

In adolescents, Logistic regression analyses also showed a negative association of lethality with females compared to males ( $\mathrm{OR}=0.09,95 \% \mathrm{CI}=0.01-0.73, \mathrm{p}=0.02$ ) (Table 5). High lethality was associated with ER visits in the evening at $18^{-}$ 24 compared to $0-6(\mathrm{OR}=14.65,95 \% \mathrm{CI}=1.18-182.52, \mathrm{p}=0.04)$ (Table 5).

\section{DISCUSSION}

In this study, we aimed to identify individual characteristics that differ according to the degree of lethality evaluated by RRRS in patients with DSP and the factors associated with higher risks of lethality for males and those who admitted their suicidal intent.

The previously published retrospective study by Oh et al. [16] demonstrated that males, advanced age, and unemployed status were associated with high-lethality suicide attempts in patients with DSP. Moreover, alcohol co-ingestion was significantly associated with high-rescue attempts [17]. Our findings of higher fatality in male and older age in patients with DSP are consistent with previous studies.

Regarding the expression of suicidal intent, our study's findings are consistent with a study by Yeum et al. [18], who demonstrated a tendency to choose a high lethality method when expressing suicide intention attempts. Our results showed that the proportion of expression of suicidal intent was significantly higher in the high lethality group. Previous studies on the relationship between lethality and suicidal intent and their association with subsequent suicides have yielded contradictory findings [19]. Our findings provide wider support to the presumption that patients intending to commit suicide need to be regarded as a group for which more efforts are required to link psychiatric treatment in the future.

The results of this study showed that the type of poisoning drugs was significantly associated with high mortality. DSP using herbicides was eight times more dangerous than OTC drugs, which were twice as dangerous as psychiatric drugs. Pesticide poisoning is the most common suicide method in Asia and is estimated to account for $30 \%$ of suicides worldwide [3,20]. In particular, Korea has made efforts to remove lethal substances from herbicides since 2012 [21]. While this has lowered the fatality rate of DSP using pesticides, it still needs to be managed because of its higher risk compared to other prescription drugs.

Around one in three patients with DSP using OTC drugs (89 cases) were from the adolescent group, and OTC overdose cases also accounted for $40 \%$ of all adolescent suicide patients [22]. Several previous studies have addressed the need to control access to drug types that increase the mor- 
Table 3. Multivariable logistic regression analysis for factors associated with high-lethality among patients with deliberate selfpoisoning $(n=491)$

\begin{tabular}{|c|c|c|c|}
\hline Variable & OR & $95 \% \mathrm{Cl}$ & $\mathrm{p}$ \\
\hline \multicolumn{4}{|l|}{ Sex } \\
\hline Male & 1.00 & & \\
\hline Female & 0.50 & $0.30-0.81$ & 0.01 \\
\hline \multicolumn{4}{|l|}{ Age $(y r)$} \\
\hline-29 & 1.00 & & \\
\hline $30-39$ & 0.71 & $0.30-1.67$ & 0.43 \\
\hline $40-49$ & 0.74 & $0.34-1.60$ & 0.44 \\
\hline $50-59$ & 0.93 & $0.44-1.93$ & 0.84 \\
\hline $60-69$ & 0.66 & $0.26-1.65$ & 0.37 \\
\hline $70-79$ & 1.80 & $0.73-4.42$ & 0.20 \\
\hline \multicolumn{4}{|l|}{ Visit time (hour) } \\
\hline $0-6$ & 1.00 & & \\
\hline $6-12$ & 0.87 & $0.38-1.98$ & 0.74 \\
\hline $12-18$ & 0.74 & $0.38-1.45$ & 0.38 \\
\hline $18-24$ & 1.04 & $0.55-1.97$ & 0.90 \\
\hline \multicolumn{4}{|l|}{ Type of poisoning drug } \\
\hline Psychiatric drugs & 1.00 & & \\
\hline Other prescribed drugs & 2.29 & $0.97-5.42$ & 0.06 \\
\hline OTC drugs & 2.49 & $1.08-5.74$ & 0.03 \\
\hline Herbicides & 8.65 & $3.91-19.13$ & $<0.01$ \\
\hline \multicolumn{4}{|l|}{ Trigger event } \\
\hline Interpersonal problems & 1.00 & & \\
\hline $\begin{array}{l}\text { Economic and social } \\
\text { problems }\end{array}$ & 1.23 & $0.64-2.40$ & 0.53 \\
\hline Others & 1.37 & $0.68-2.78$ & 0.38 \\
\hline Unknown & 1.36 & $0.69-2.67$ & 0.38 \\
\hline \multicolumn{4}{|l|}{ Treatment consent } \\
\hline $\begin{array}{l}\text { Refusing psychiatric } \\
\text { treatment }\end{array}$ & 1.00 & & \\
\hline $\begin{array}{l}\text { Consenting to psychiatric } \\
\text { treatment }\end{array}$ & 0.99 & $0.52-1.88$ & 0.97 \\
\hline \multicolumn{4}{|l|}{ Previous suicide attempts } \\
\hline No & 1.00 & & \\
\hline Yes & 0.81 & $0.41-1.59$ & 0.54 \\
\hline \multicolumn{4}{|l|}{ Psychiatric treatment history } \\
\hline None & 1.00 & & \\
\hline In treatment & 0.92 & $0.29-2.94$ & 0.89 \\
\hline Previous history & 0.36 & $0.08-1.55$ & 0.17 \\
\hline \multicolumn{4}{|l|}{ Blood alcohol levels (mg/dL) } \\
\hline 0 & 1.00 & & \\
\hline-150 & 1.12 & $0.61-2.07$ & 0.71 \\
\hline$>150$ & 1.61 & $0.82-3.15$ & 0.17 \\
\hline \multicolumn{4}{|l|}{ Suicide intent expression } \\
\hline Admit & 1.00 & & \\
\hline Denial & 0.28 & $0.15-0.55$ & $<0.01$ \\
\hline Unmeasured & 0.72 & $0.40-1.29$ & 0.26 \\
\hline
\end{tabular}

Table 3. Multivariable logistic regression analysis for factors associated with high-lethality among patients with deliberate selfpoisoning $(n=491)$ (continued)

\begin{tabular}{|c|c|c|c|}
\hline Variable & OR & $95 \% \mathrm{Cl}$ & $\mathrm{p}$ \\
\hline \multicolumn{4}{|c|}{ Number of outpatient visits after discharge } \\
\hline 0 & 1.00 & & \\
\hline $1-9$ & 0.72 & $0.38-1.37$ & 0.31 \\
\hline $10-$ & 0.36 & $0.12-1.08$ & 0.07 \\
\hline \multicolumn{4}{|c|}{ Last psychiatric outpatient visit } \\
\hline None & 1.00 & & \\
\hline Within one week & 1.62 & $0.39-6.66$ & 0.51 \\
\hline Within one month & 1.58 & $0.44-5.73$ & 0.49 \\
\hline More than one month & 2.69 & $0.67-10.88$ & 0.17 \\
\hline \multicolumn{4}{|c|}{ Previous psychiatric admission } \\
\hline None & 1.00 & & \\
\hline Once & 1.12 & $0.44-2.88$ & 0.81 \\
\hline Multiple & 0.96 & $0.36-2.51$ & 0.93 \\
\hline
\end{tabular}

tality rate of drug overdose [22]. An implication of our findings is the potential for careful management of OTC drugs that can be a way to reduce adolescents' suicide attempts.

Previous research has shown that patients with DSP are usually more likely to take prescribed medications [23]. The results of this study show that psychiatric and other prescription drugs account for $44 \%$ and $22 \%$, respectively, amounting to a total of $66 \%$. Among the types of drugs, lethality was low when DSP was attempted with psychiatric drugs because patients with DSP having psychiatric drugs were more likely to consult their psychiatrists and take the prescribed drugs. In cases of DSP with psychiatric drugs, it can be said that the patients were under psychiatric treatment either in the past or present. Therefore, it can be presumed that among the groups of patients attempting DSP, the group of patients with psychiatric follow-up is in safer positions comparatively.

According to a US study, the frequency and incidence of DSP suicide attempts have increased significantly in children under 19 years of age, and the severity of the outcome has increased, regardless of age or gender [8]. This highlights the need for in-depth research on DSP in adolescent groups. Our analysis of the adolescent group indicated that sex and drinking status were associated with suicide fatality. Excessive drinking is a clear risk factor for suicidal behavior in young adolescents, beyond the risk conveyed by depressive symptoms [24]. In this study, alcohol use in adolescents was also found to be associated with high lethality DSP, so it should be considered as a factor with caution in the clinical field.

In this study, $48 \%$ of adolescent groups had more than one outpatient follow up after the DSP event, which was higher 
Table 4. Comparison of sociodemographic and clinical characteristics of adolescent patients aged 9-24 with deliberate self-poisoning by quartiles of RRRS

\begin{tabular}{|c|c|c|c|c|c|}
\hline Variable & Q1 $(n=26)$ & Q2 $(n=33)$ & Q3 $(n=10)$ & Q4 $(n=7)$ & $\mathrm{p}$ \\
\hline Sex & & & & & $0.009^{\dagger}$ \\
\hline Male & $9(35)$ & $5(15)$ & $5(50)$ & $5(71)$ & \\
\hline Female & $17(65)$ & $28(85)$ & $5(50)$ & $2(29)$ & \\
\hline Visit time (hour) & & & & & 0.464 \\
\hline $0-6$ & $10(38)$ & $7(21)$ & $2(20)$ & $3(43)$ & \\
\hline $6-12$ & $5(19)$ & $6(18)$ & $2(20)$ & $1(14)$ & \\
\hline $12-18$ & $6(23)$ & $13(39)$ & $2(20)$ & $0(0)$ & \\
\hline $18-24$ & $5(19)$ & $7(21)$ & $4(40)$ & $3(43)$ & \\
\hline Trigger event & & & & & 0.753 \\
\hline Interpersonal problems & $14(54)$ & $14(42)$ & $4(40)$ & $3(43)$ & \\
\hline Economic and social problem & $2(8)$ & $10(30)$ & $2(20)$ & $2(29)$ & \\
\hline Others & $5(19)$ & $4(12)$ & $2(20)$ & $1(14)$ & \\
\hline Unknown & $5(19)$ & $5(15)$ & $2(20)$ & $1(14)$ & \\
\hline Suicide intent expression & & & & & 0.694 \\
\hline Admit & $12(46)$ & $17(52)$ & $5(50)$ & $5(71)$ & \\
\hline Denial & $9(35)$ & $9(27)$ & $2(20)$ & $0(0)$ & \\
\hline Unmeasured & $5(19)$ & $7(21)$ & $3(30)$ & $2(29)$ & \\
\hline Type of poisoning drug & & & & & 0.106 \\
\hline Psychiatric drug & $12(46)$ & $22(67)$ & $3(30)$ & $3(43)$ & \\
\hline Other prescribed drug & $0(0)$ & $0(0)$ & $1(10)$ & $1(14)$ & \\
\hline OTC drug & $11(42)$ & $10(30)$ & $6(60)$ & $3(43)$ & \\
\hline Herbicide & $3(12)$ & $1(3)$ & $0(0)$ & $0(0)$ & \\
\hline Blood alcohol level (mg/dL) & & & & & $0.049 *$ \\
\hline 0 & $23(88)$ & $29(88)$ & $65(94)$ & $4(57)$ & \\
\hline-150 & $3(12)$ & $3(9)$ & $4(6)$ & $2(29)$ & \\
\hline$>150$ & $0(0)$ & $1(3)$ & $0(0)$ & $1(14)$ & \\
\hline Psychiatric treatment history & & & & & 0.149 \\
\hline None & $13(50)$ & $8(24)$ & $5(50)$ & $3(43)$ & \\
\hline In treatment & $13(50)$ & $20(61)$ & $4(4)$ & $3(43)$ & \\
\hline Previous history & $0(0)$ & $5(15)$ & $1(10)$ & $1(14)$ & \\
\hline Previous suicide attempt & & & & & 0.196 \\
\hline No & $21(81)$ & $21(64)$ & $7(70)$ & $7(100)$ & \\
\hline Yes & $5(19)$ & $12(36)$ & $3(30)$ & $0(0)$ & \\
\hline Previous psychiatric admission & & & & & 1.000 \\
\hline None & $22(88)$ & $27(82)$ & $9(90)$ & $7(100)$ & \\
\hline Once & $3(12)$ & $4(12)$ & $1(10)$ & $0(0)$ & \\
\hline Multiple & $1(0)$ & $2(6)$ & $0(0)$ & $0(0)$ & \\
\hline Last psychiatric outpatient visit & & & & & 0.224 \\
\hline None & $11(42)$ & $7(21)$ & $3(30)$ & $3(38)$ & \\
\hline Within 1 week & $4(15)$ & $8(24)$ & $0(0)$ & $1(13)$ & \\
\hline Within 1 month & $10(38)$ & $12(36)$ & $3(30)$ & $2(25)$ & \\
\hline More than 1 month & $1(4)$ & $6(18)$ & $4(40)$ & $2(25)$ & \\
\hline Psychiatric treatment consent & & & & & 0.308 \\
\hline Refusal to treatment & $13(50)$ & $17(52)$ & $8(80)$ & $5(20)$ & \\
\hline Consent to treatment & $13(50)$ & $16(48)$ & $2(20)$ & $20(80)$ & \\
\hline Number of outpatient visits after discharge & & & & & 0.694 \\
\hline 0 & $9(35)$ & $18(55)$ & $6(60)$ & $6(86)$ & \\
\hline $1-9$ & $15(58)$ & $8(24)$ & $3(30)$ & $1(14)$ & \\
\hline $10-$ & $2(8)$ & $7(21)$ & $1(10)$ & $0(0)$ & \\
\hline
\end{tabular}


Table 5. Multivariable logistic regression analysis for factors associated with high-lethality among adolescent patients aged 9-24 with deliberate self-poisoning

\begin{tabular}{|c|c|c|c|}
\hline Variable & OR & $95 \% \mathrm{Cl}$ & $\mathrm{p}$ \\
\hline \multicolumn{4}{|l|}{ Sex } \\
\hline Male & 1.00 & & \\
\hline Female & 0.09 & $0.01-0.73$ & $0.02^{*}$ \\
\hline \multicolumn{4}{|l|}{ Visit time (hour) } \\
\hline $0-6$ & 1.00 & & \\
\hline $6-12$ & 1.93 & $0.16-23.67$ & 0.61 \\
\hline $12-18$ & 0.26 & $0.01-5.41$ & 0.39 \\
\hline $18-24$ & 14.65 & $1.18-182.52$ & 0.04 \\
\hline \multicolumn{4}{|l|}{ Trigger event } \\
\hline Interpersonal problems & 1.00 & & \\
\hline $\begin{array}{l}\text { Economic and social } \\
\text { problem }\end{array}$ & 1.24 & $0.08-18.17$ & 0.88 \\
\hline Others & 6.41 & $0.31-132.45$ & 0.23 \\
\hline Unknown & 2.99 & $0.20-43.82$ & 0.42 \\
\hline \multicolumn{4}{|l|}{ Treatment consent } \\
\hline $\begin{array}{l}\text { Refusal to psychiatric } \\
\text { treatment }\end{array}$ & 1.00 & & \\
\hline $\begin{array}{l}\text { Consent to psychiatric } \\
\text { treatment }\end{array}$ & 0.16 & $0.02-1.66$ & 0.12 \\
\hline \multicolumn{4}{|l|}{ Previous suicide attempt } \\
\hline No & 1.00 & & \\
\hline Yes & 1.48 & $0.06-35.15$ & 0.81 \\
\hline \multicolumn{4}{|l|}{ Psychiatric treatment history } \\
\hline None & 1.00 & & \\
\hline In treatment & 0.09 & $0.01-0.98$ & 0.05 \\
\hline Previous history & 0.07 & $0.00-4.59$ & 0.21 \\
\hline \multicolumn{4}{|l|}{ Blood alcohol level (mg/dL) } \\
\hline 0 & 1.00 & & \\
\hline-150 & 13.24 & $1.16-150.77$ & $0.04^{*}$ \\
\hline$>150$ & 1.67 & $0.03-81.27$ & 0.79 \\
\hline \multicolumn{4}{|l|}{ Suicide intent expression } \\
\hline Admit & 1.00 & & \\
\hline Denial & 0.11 & $0.01-1.71$ & 0.12 \\
\hline Unmeasured & 3.74 & $0.39-36.13$ & 0.25 \\
\hline \multicolumn{4}{|c|}{ Number of outpatient visits after discharge } \\
\hline 0 & 1.00 & & \\
\hline $1-9$ & 0.17 & $0.01-2.03$ & 0.16 \\
\hline $10-$ & 0.03 & $0.00-3.73$ & 0.15 \\
\hline
\end{tabular}

* $\mathrm{p}<0.05$. OR: odds ratios, $\mathrm{Cl}$ : confidence intervals, OTC drug: over-the-counter drugs (medicines sold directly to a consumer without a requirement for a prescription from a healthcare professional)

than that of the adult and elderly groups. About half of adolescents with DSP who visited the outpatient can be seen as an act of help-seeking. It is important to use this as an opportunity to establish a good therapeutic relationship with adolescents at-risk and continue treatment. These results sug- gest the attitudes of the patients with DSP should be directed toward help-seeking and treatment in the adolescent group. Lethality measured by RRRS was higher in adolescents who visited the ED in the evening (18-24 hours) than in the early morning hours (0-6 hours). According to previous studies, the time at which adolescents visited the ED was related to DSP because self-harm behavior increased during the evening hours. A possible reason for this pattern is that since adolescents often do not visit the ED themselves, but are taken by their parents; there is the possibility that parents on recognizing their child's condition bring them to the ED, which is likely to be in the evenings, the time when they return home from work [25]. Unlike the previous study's results [25], the number of patients who visited between 0-6 hours and 1218 hours was found to be higher than the number of patients who visited during 18-24 hours. However, the lethality of suicide attempts was higher in the group of adolescent patients who visited during the evenings (18-24 hours). The relationship between the lethality of suicide attempts and ED visit time is likely to be similar to the previously mentioned reason. It can be assumed that these patients had been left unattended until their parents discovered their condition, which could have been delayed until the evening.

We found $75 \%$ of patients with DSP were first attempters. A first self-poisoning episode is a strong predictor of subsequent suicides. The lethality of the patients' index (most recent suicidal episode at hospitalization), first, and worst suicide attempts predicted the lethality of the worst suicide attempt during a two-year follow-up period [26]. It has been reported that subsequent attempts to improve their success rate were retried after the first suicide attempt failed [27]. Although the majority of patients with DSP appeared to be firsttime suicide attempters, and their self-poisoning attempts were non-lethal, there could be a progression towards high lethality suicidal behavior. Many people who committed suicide and eventually died had been in contact with healthcare professionals in acute hospitals and/or primary or secondary care prior to their deaths. Around one in four suicides occurred among people who had been in contact with mental health services in the year before their death in the UK, and around one in three in the US [28]. Later, it is necessary to plan the long-term perspective by tracing the trajectory of patients with DSP's medical use status, for which the Health Insurance Review \& Assessment Service uses systems such as the resident registration number. Therefore, timely followup with patients after the first episode of DSP could be an important preventive measure to reduce suicide rates in the future.

For treating patients with risk factors for serious suicide attempts, the introduction of a case management system, irrespective of whether the patient consents, along with intensive 
services for strengthening outpatient treatment compliance, could help mitigate future risk of patients demonstrating a higher lethality of attempting suicide.

This study has several limitations to be considered. First, although it was conducted in the regional emergency medical center of a large hospital, it is difficult to generalize its results because it was conducted in a single institution. Thus, it was not possible to track the utilization pattern of healthcare facilities. Therefore, future studies that utilize big data analytics of national health insurance will be needed. Second, except for RRRS, no other objective tool or instrument was used to assess patients with DSP's psychiatric conditions.

Despite these limitations, our study has the strengths that examined specific age groups, aged under 24 years, which is high in patients with DSP. This study also investigated the relationship between the severity and lethality of DSP, the history of psychiatric treatment, and the rates of psychiatric treatment linkage after the DSP. Although this study was initially designed to identify the variables associated with psychiatric treatment linkage, no statistical significance was observed.

\section{CONCLUSION}

This study showed the clinical factors associated with the high mortality rate of DSP. This suggests that efforts are needed because DSP is often selected as the method for the first suicide attempt, due to the lack of adequate psychiatric links or follow-up measures in the ED, and the absence of a means to enforce them. For this plan, it is necessary to develop an institutional reform plan for patients with DSP and develop a policy for an efficient national mental health system by improving mental health-related institutions. In the group of adolescent patients, there is a need for an institutional policy with treatment through a direct connection to school or home as an outpatient treatment order system in adults.

\section{Acknowledgments}

This study was supported by the Bumsuk Academic Research Fund in 2019. Part of the study results was presented as a poster at the Korean Neuropsychiatric Association's regional meeting on October $18,2019$.

\section{Conflicts of Interest}

The authors have no potential conflicts of interest to disclose.

\section{Author Contributions}

Conceptualization: Minha Hong, In Young Choi. Data curation: In Young Choi. Formal analysis: Sun-Young Kim. Investigation: Hoo Rim Song, Su Young Lee, Jhin Goo Chang, Woo Jung Kim, Hyun Soo Kim. Writing_original draft: Minha Hong, In Young Choi. Writing_review and editing: Hoo Rim Song, Minha Hong, In Young Choi.

\section{ORCID iDs}

In Young Choi

https://orcid.org/0000-0003-0318-8734

Sun-Young Kim

https://orcid.org/0000-0002-7110-3395

Jhin Goo Chang

https://orcid.org/0000-0003-3024-4893

Hoo Rim Song

https://orcid.org/0000-0001-8927-0530

Woo Jung Kim

https://orcid.org/0000-0002-4963-4819

Su Young Lee

https://orcid.org/0000-0003-3125-3409

Hyun-Soo Kim

https://orcid.org/0000-0002-6219-8820

Min Ha Hong

https://orcid.org/0000-0003-4924-1107

\section{REFERENCES}

1) Ministry of Health and Welfare. 2018 National survey on suicide [cited 2020 Mar 20]. Available from URL: http://www.mohw. go.kr/react/jb/sjb030301vw.jsp.

2) National Health Insurance Service Health Insurance Policy Institute. [Analysis of socio-economic costs of major diseases for setting priorities for health insurance policy]. Wonju: National Health Insurance Service Health Insurance Policy Institute;2017.

3) World Health Organization. Preventing suicide: a global imperative. Luxembourg: World Health Organization;2014.

4) Owens D, Horrocks J, House A. Fatal and non-fatal repetition of self-harm. Systematic review. Br J Psychiatry 2002;181:193-199.

5) Bergen H, Hawton K, Waters K, Ness J, Cooper J, Steeg S, et al. Premature death after self-harm: a multicentre cohort study. Lancet 2012;380:1568-1574.

6) Nock MK, Favazza AR. Nonsuicidal self-injury: definition and classification. In: Nock MK, editor. Understanding nonsuicidal self-injury: origins, assessment, and treatment. American Psychological Association;2009.

7) Swannell SV, Martin GE, Page A, Hasking P, St John NJ. Prevalence of nonsuicidal self-injury in nonclinical samples: systematic review, meta-analysis and meta-regression. Suicide Life Threat Behav 2014;44:273-303.

8) Spiller HA, Ackerman JP, Spiller NE, Casavant MJ. Sex- and agespecific increases in suicide attempts by self-poisoning in the United States among youth and young adults from 2000 to 2018. J Pediatr 2019;210:201-208.

9) Ministry of Health and Welfare; Korea Suicide Prevention Center. 2020 Suicide prevention white paper. Seoul: Korea Suicide Prevention Center;2020.

10) Finkelstein Y, Macdonald EM, Hollands S, Hutson JR, Sivilotti ML, Mamdani MM, et al. Long-term outcomes following self-poisoning in adolescents: a population-based cohort study. Lancet Psychiatry 2015;2:532-539.

11) National Institute for Health and Care Excellence. Self-harm in over 8s: short-term management and prevention of recurrence [cited 2020 Mar 20]. Available from URL: https://www.nice.org. uk/guidance/cg16.

12) Kim DW, Jeong KY, Kim KS. Psychological scales as predictors of emergency department hospitalizations in suicide attempters. Am J Emerg Med 2018;36:93-99.

13) Weisman AD, Worden JW. Risk-rescue rating in suicide assessment. Arch Gen Psychiatry 1972;26:553-560.

14) Patterson D, Fay J. Contemporary security management. 4th ed. Oxford: Butterworth-Heinemann;2017.

15) Spooren D, Van Heeringen C, Jannes C. Strategies to increase compliance with out-patient aftercare among patients referred to a psychiatric emergency department: a multi-centre controlled intervention study. Psychol Med 1998;28:949-956.

16) Oh SH, Kim HJ, Kim SH, Kim YM, Park KN. Which deliberate self-poisoning patients are most likely to make high-lethality suicide attempts? Int J Ment Health Syst 2015;9:35. 
17) Jung WY, Park JM, Kang CJ, Lee BD, Lee YM. Clinical characteristics of completed versus non-completed suicide and re-attempt rates in 2-4 years. J Korean Neuropsychiatr Assoc 2009;48:488-495.

18) Yeum TS, Kim B, Kim EY, Kim SH, Ha K, Ahn YM. Factors affecting suicide method lethality among suicide attempters in the Korea national suicide survey. J Nerv Ment Dis 2018;206:202-210.

19) Gjelsvik B, Heyerdahl F, Holmes J, Lunn D, Hawton K. Is there a relationship between suicidal intent and lethality in deliberate selfpoisoning? Suicide Life Threat Behav 2017;47:205-216.

20) Wu M, Zheng M, Zhang W, Suresh S, Schlecht U, Fitch WL, et al. Identification of drug targets by chemogenomic and metabolomic profiling in yeast. Pharmacogenet Genomics 2012;22:877-886.

21) Korea Law Information Center. [AGROCHEMICALS CONTROL ACT] [cited 2020 Mar 20]. Available from URL: https://www.law. go.kr/법령/농약관리법.

22) Miller TR, Swedler DI, Lawrence BA, Ali B, Rockett IRH, Carlson $\mathrm{NN}$, et al. Incidence and lethality of suicidal overdoses by drug class. JAMA Netw Open 2020;3:e200607.

23) Gjelsvik B, Heyerdahl F, Hawton K. Prescribed medication availability and deliberate self-poisoning: a longitudinal study. J Clin Psychiatry 2012;73:e548-e554.
24) Aseltine RH Jr, Schilling EA, James A, Glanovsky JL, Jacobs D. Age variability in the association between heavy episodic drinking and adolescent suicide attempts: findings from a large-scale, schoolbased screening program. J Am Acad Child Adolesc Psychiatry 2009; 48:262-270

25) Ali S, Rosychuk RJ, Dong KA, McGrath PJ, Newton AS. Temporal trends in pediatric mental health visits: using longitudinal data to inform emergency department health care planning. Pediatr Emerg Care 2012;28:620-625.

26) Rojas SM, Skinner KD, Feldner MT, Rodante DE, Puppo S, Vidjen P, et al. Lethality of previous suicidal behavior among patients hospitalized for suicide risk predicts lethality of future suicide attempts. Suicide Life Threat Behav 2019;49:1431-1438.

27) Wang LJ, Huang YC, Lee SY, Wu YW, Chen CK. Switching suicide methods as a predictor of completed suicide in individuals with repeated self-harm: a community cohort study in northern Taiwan. Aust N Z J Psychiatry 2015;49:65-73.

28) Gairin I, House A, Owens D. Attendance at the accident and emergency department in the year before suicide: retrospective study. $\mathrm{Br}$ J Psychiatry 2003;183:28-33. 